\title{
Influence of cooling face masks on nasal air conditioning and nasal geometry*
}

\author{
Joerg Lindemann', Thomas Hoffmann', Andreas Koehl', Eva-Maria Walz', \\ Fabian Sommer \\ ' Department of Otorhinolaryngology, University of UIm, UIm, Germany \\ 2 Department of Otorhinolaryngology, Hospital of Magdeburg, Magdeburg, Germany
}

Rhinology 55: 120-125, 2017

https:://doi.org/10.4193/Rhino16.212

*Received for publication:

July 7, 2016

Accepted: October 6, 2016

\begin{abstract}
Introduction: Nasal geometries and temperature of the nasal mucosa are the primary factors affecting nasal air conditioning. Data on intranasal air conditioning after provoking the trigeminal nerve with a cold stimulus simulating the effects of an arctic condition is still missing. The objective was to investigate the influence of skin cooling face masks on nasal air conditioning, mucosal temperature and nasal geometry.

Methods: Standardized in vivo measurements of intranasal air temperature, humidity and mucosal temperature were performed in 55 healthy subjects at defined detection sites before and after wearing a cooling face mask. Measurements of skin temperature, rhinomanometry and acoustic rhinometry were accomplished.
\end{abstract}

Results: After wearing the face mask the facial skin temperature was significantly reduced. Intranasal air temperature did not change. Absolute humidity and mucosal temperature increased significantly. The acoustic rhinometric results showed a significant increase of the volumes and the cross-sectional areas. There was no change in nasal airflow.

Conclusions: Nasal mucosal temperature, humidity of inhaled air, and volume of the anterior nose increased after application of a cold face mask. The response is mediated by the trigeminal nerve. Increased mucosal temperatures as well as changes in nasal geometries seem to guarantee sufficient steady intranasal nasal air conditioning.

Key words: mucosal temperature, cooling mask, air conditioning, active anterior rhinomanometry, acoustic rhinometry

\section{Introduction}

One of the main functions of the nose is air conditioning. There are different regions in the nose. The anterior nasal segment, including the nasal valve area and the anterior turbinate area, is the most effective part of the nasal airway for heating and humidification of inhaled air ${ }^{(1-4)}$.

Anthropologic studies show a close relationship between morphologic features of the human nasal skeleton and geographic climate $^{(5,6)}$. Variations in nasal valve angles have been described and morphologic variations of the human nose have been attributed to climatic adaptation. Nasal cavities have been broadly categorized as tall and narrow (leptorrhines) or short and broad (platyrrhines), e.g. Arabs compared to Africans ${ }^{(7)}$. These variati- ons suggests that adequate nasal air conditioning is essential for ideal pulmonary gas exchange to avoid drying and adhesions of the interface at the alveolar-capillary bed. Additionally, the human nose needs to adapt constantly to varying climatic conditions (e.g., changes of seasons, air conditioning) to keep the intranasal climate constant. Nasal air conditioning and its dependence on external factors are not completely understood. Due to the trigeminal link between facial skin and nasal mucosa, a short-term cooling of the facial skin was assumed to influence intranasal air conditioning. Therefore, the objective of this study was to identify intranasal changes mediated by change in the temperature of the facial skin induced by external application of a cold face mask. Nasal air conditioning, mucosal temperature, 
and intranasal geometry were in-vivo analysed.

\section{Materials and methods}

The study was performed after receiving approval of the local ethics committee (Ethics Committee of the University of Ulm). All experimental procedures were fully explained to the study participants who provided written informed consent.

\section{Volunteers}

A total of 55 healthy subjects ( 29 males, 26 females) with normal nasal anatomy and with a median age of 36 years (range, 21 77 years) were included in the study. The age distribution was chosen to examine a representative group. All study participants were screened with complete otorhinolaryngological examination including anterior rhinoscopy and nasal endoscopy. Patient with even a small septal deviation, septal spurs, - crests or signs of turbinate hypertrophy were excluded. The participants had no nasal complaints, no anamnestic symptoms of chronic rhinosinusitis, no nasal surgery, trauma or allergy, and did not take any medication eight weeks prior to the examination. All participants enjoyed good health.

\section{Measurement of facial skin temperature}

Facial skin temperature was measured with an infrared thermometer SANITAS SFT 41 (Beurer GmbH \& Co., Ulm, Germany) with a wide measuring tip. This thermometer provided fast and reliable results in a few seconds and with an accuracy of $\pm 0.3^{\circ} \mathrm{C}$. Temperatures were measured on the right and left cheeks in the midorbital line $3 \mathrm{~cm}$ below the infraorbital rim.

\section{Recording of intranasal humidity and temperature}

Our working group standardized the technique for in vivo measurements of intranasal humidity and temperature. The equipment for intranasal temperature and humidity measurements within the air stream has been described in detail ${ }^{(3,4,8-10)}$.

A capacitive thin-film humidity sensor (Humichip 17204 HM, Vaisala, Vantaa, Finland) was applied to detect the relative humidity (RH). The capacitance of the sensor's polymer film changes with absorption of water and reflects relative humidity. The humidity sensor was enclosed in an acrylic box and was connected to a calibrated suction system. The air was transported to the humidity sensor via a heated silicon suction probe. The apparatus permitted measurement of RH between 0 and 100\%. In highvelocity air, less than two seconds was needed to reach $90 \%$ of the steady-state. Air temperature and $\mathrm{RH}$ were used to calculate absolute humidity in $\mathrm{g} / \mathrm{m}^{3}$ at the end of inspiration.

Intranasal air temperature was measured by a miniaturized thermocouple (thermocouple type $\mathrm{K}$ thermoelectric wire consisting of Chromel and Alumel, Thermocoax, Suresnes, France, technical temperature range -200 to $+800^{\circ} \mathrm{C}$ ) with an outer diameter of $0.34 \mathrm{~mm}$. Its response time in stagnant air is 0.4 seconds and in high-velocity air is 0.1 seconds. Simultaneous analysis of humidity and temperature was achieved by attaching the thermocouple to the suction probe of the humidity sensor. Measurements of the nasal mucosal temperature were acquired by an identical thermocouple without the silicone tube. The placement of instruments was standardized in previous studies ${ }^{(8-10)}$.

The temperature and humidity data were amplified and transferred to a computer via an analog-to-digital card. Continuous registration was acquired by the computer program Turbo Lab (Bressner Technology, Munich, Germany). Respiratory cycles of one minute were analyzed. The mean end-inspiratory temperature and relative humidity of one respiratory cycle were calculated after a minimum of five consecutive respiratory cycles showing a temperature deviation less than $3 \%$ at the end of inspiration. In cases of wider variation, measurements were repeated after an interval of five minutes. The respiratory cycle was detected using a stress-sensitive belt around the thorax (MAP, Martinsried, Germany).

All subjects were adapted to the laboratory environment (mean room temperature $22^{\circ} \mathrm{C}$, mean relative humidity $22 \%$ ) for 30 minutes by quietly breathing through the nose in an upright position before measurements were acquired.

The space between the nasal valve area and the head of the middle turbinate is the most effective part of the nasal cavity for heating and humidification of intranasal air. We therefore placed the sensor within the nasal valve area close to the head of the inferior turbinate or within the anterior turbinate area close to the head of the middle turbinate through a nasal speculum while guided by a headlight. Correct position was confirmed by nasal endoscopy. The heads of the subjects were gently stabilized in a head holder. Right and left nasal cavities were examined without decongestion or topical anesthesia. Humidity and temperature of the nasal air stream in both nasal cavities were continuously recorded during quiet breathing for one minute.

Temperature measurements of the nasal mucosa were then acquired by gently placing the thermocouple on the mucosal surface of the septum. The sensor was consecutively positioned in the nasal valve area close to the head of the inferior turbinate and in the anterior turbinate area close to the head of the middle turbinate. We did not observe mucosal irritation by touching the mucosal surface with the thermocouple ${ }^{(8-10)}$.

Active anterior rhinomanometry (AAR) and acoustic rhinometry (AR)

All measurements were performed consistent with the recom- 
mendations of the International Standardization Committee for rhinomanometry and acoustic rhinometry ${ }^{(11)}$

After the adaptation period, active anterior rhinomanometry (model: Rhinomanometer 300; Atmos, Lenzkirch, Germany; transnasal reference pressure, $150 \mathrm{~Pa}$ ) was performed in both nasal cavities. The rhinomanometer was calibrated before each use. Three to five nasal breaths were used to average the results according to the congruence of the curves.

Acoustic rhinometry (model: SRE 2000, RhinoMetrics, Lynge, Denmark) was also performed on all volunteers. At least three measurements from each nostril were acquired. The following median minimal cross-sectional areas (MCA) and nasal volumes (Vol) were calculated: MCA 1 (0-20 mm from the nasal entrance), MCA 2 (20-50 mm from the nasal entrance), Vol 1 (0-20 mm from the nasal entrance), and $\mathrm{Vol} 2$ (20-50 $\mathrm{mm}$ from the nasal entrance). External noise, room temperature and humidity, and the angle of the sound wave tube were kept constant.

\section{Cooling face mask}

Different types of face masks were tested to obtain optimal cooling of the facial skin. The ideal mask would cover the entire face to stimulate thermal skin receptors. The "Hot-Cold Face Mask" by Dr. Winkler GmbH \& Co (Ainring-Mitterfelden, Germany) was selected because it covers the entire face while sparing the eyes, nose, and mouth and it permits the planned measurements. Adjustable Velcro straps allow the mask to be fixed to the head with the patient in an upright, sitting position. These masks are usually used for cooling after facial treatments and surgical procedures (Figure 1). The volunteers did not feel uncomfortable wearing the mask for 10 minutes.

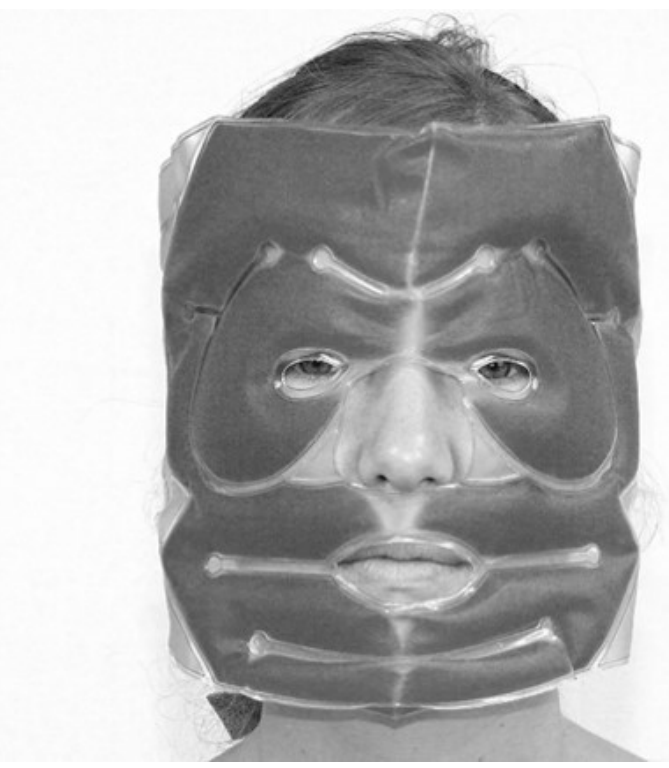

Figure 1. The Hot-Cold Face Mask.

\section{Sequence of the measurements}

The measurements were performed in this standardized order on all subjects:

Prior to placing the cooling mask:

1. Intranasal air temperature and humidity.

2. Temperature of the nasal mucosa.

3. AR and AAR.

4. Facial skin temperature.

The face mask, cooled to zero ${ }^{\circ} \mathrm{C}$, was then applied for $10 \mathrm{mi}-$ nutes.

With applied cold mask:

1. Intranasal air temperature and humidity.

2. Temperature of the nasal mucosa.

3. AR.

After removing the cold mask:

4. AAR.

5. Facial skin temperature.

The cold mask remained on the face during the temperature and humidity measurements and during $A R$; data were acquired through the nasal gap in the mask without loss of cooling. The mask had to be removed for the AAR and facial skin temperature measurements.

\section{Statistical analysis}

WinSTAT ${ }^{\circledR}$ for MS Excel ${ }^{\circledR}$ Version 2007.1 (Kalmia Inc., Cambridge, MA, U.S.A.) was used as a statistics program.

The statistical evaluation of the measured values was performed using the Wilcoxon test as a non-parametric test for paired samples for the comparison of the values before and after wearing the face mask. The null hypothesis (no difference between the corresponding values) was rejected at $\mathrm{p}<0.05$.

\section{Results}

A complete set of data was achieved for all 55 participants. There was no individual or technical problem inserting the sensors into the nasal cavities. Temporary endoscopic control and mucosal adaptation prior to measurements were sufficient to avoid mucosal irritation by the sensors. The results of the investigations were not age-dependent.

\section{Facial skin temperature}

Initially the median temperature of the facial skin was $31.2^{\circ} \mathrm{C}$. The median temperature of the facial skin was cooled down to $21.0^{\circ} \mathrm{C}(\mathrm{p}<0.001)$. The median temperature difference before and after wearing the face mask was $9.9^{\circ} \mathrm{C}$.

\section{Intranasal air temperature and humidity}

The median end-inspiratory temperature and absolute humidity values before and after wearing the face mask are presented in Table 1. 
Table 1. Median air temperature (Air temp) and absolute humidity (aH) as well mucosal temperature (Mucosal temp) before and after cooling mask. (nasal valve area (NVA), anterior turbinate area (ATA), non significant (n.s.))

\begin{tabular}{|c|c|c|c|c|c|c|}
\hline & $\begin{array}{c}\text { Air } \\
\text { temp } \\
\left({ }^{\circ} \mathrm{C}\right) \\
\text { NVA }\end{array}$ & $\begin{array}{c}\text { Air } \\
\text { temp } \\
\left({ }^{\circ} \mathrm{C}\right) \\
\text { ATA }\end{array}$ & $\begin{array}{c}a H \\
\left(\mathrm{~g} / \mathrm{m}^{3}\right) \\
\text { NVA }\end{array}$ & $\begin{array}{c}\mathrm{aH} \\
\left(\mathrm{g} / \mathrm{m}^{3}\right) \\
\text { ATA }\end{array}$ & $\begin{array}{c}\text { Mu- } \\
\text { cosal } \\
\text { temp } \\
\left({ }^{\circ} \mathrm{C}\right) \\
\text { NVA }\end{array}$ & $\begin{array}{c}\text { Mu- } \\
\text { cosal } \\
\text { temp } \\
\left({ }^{\circ} \mathrm{C}\right) \\
\text { ATA }\end{array}$ \\
\hline $\begin{array}{c}\text { Before } \\
\text { mask }\end{array}$ & 23.9 & 24.2 & 12.6 & 15.8 & 28.0 & 29.3 \\
\hline $\begin{array}{l}\text { After } \\
\text { mask }\end{array}$ & 23.8 & 24.0 & 14.6 & 17.4 & 29.4 & 30.9 \\
\hline $\begin{array}{c}\mathrm{p}^{-} \\
\text {values }\end{array}$ & n.s. & n.s. & $p<0.05$ & $p<0.05$ & $p<0.05$ & $p<0.05$ \\
\hline
\end{tabular}

There was no statistical difference between the intranasal air temperatures before and after facial cooling ( $p>0.05$ ).

However, the changes of the intranasal absolute humidity were statistically significant $(p<0.001)$.

\section{Intranasal mucosa temperature}

The median temperature of the nasal mucosa increased significantly after wearing the face mask $(p<0.001)$. At the nasal valve area, the septal temperature was $28.0^{\circ} \mathrm{C}$ before and $29.4^{\circ} \mathrm{C}$ after mask application. At the anterior turbinate area, the temperature was $29.3^{\circ} \mathrm{C}$ before and $30.9^{\circ} \mathrm{C}$ after mask application.

\section{Active anterior rhinomanometry (AAR) and acoustic rhino- metry (AR)}

There was no statistically significant difference between the median unilateral flow rate in AAR before $(257 \mathrm{ml} / \mathrm{s})$ and after $(279 \mathrm{ml} / \mathrm{s}$ ) face mask application ( $p>0.05)$.

Statistical analysis of the AR showed a significant increase in MCA 1 (at a mean distance of $1.4 \mathrm{~cm}$ from the nasal entrance) and MCA 2 (at a mean distance of $2.6 \mathrm{~cm}$ from the nasal entrance) after application of the face mask $(p<0.001)$. Vol 1 was also significantly increased $(p<0.001$ ) but Vol 2 did not significantly change $(p>0.05)$. The median values of AR are presented in Table 2.

\section{Discussion}

Because of constantly changing conditions of ambient air, the nose, as the first part of the respiratory tract, is especially important to acclimatize inhaled air. Seasonal changes cause temperature and humidity variations; indoor air conditioning and heating make even higher acclimatization demands. Cold stimuli present a particular challenge to these functions. Temperature and humidity of inhaled air need to be raised within the nose which extends only a few centimetres. Stimulation by cold
Table 2. Median values of the AR before and after cooling mask. (Minimal cross-sectional areas (MCA), nasal volumes (VOL), 0-20mm (1) and 20-50mm (2) from the nasal entrance, non significant (n.s.))

\begin{tabular}{|lccc|}
\hline & Before Mask & After Mask & p-values \\
\hline MCA 1 $\left(\mathrm{cm}^{2}\right)$ & $0.6 \mathrm{~cm}^{2}$ & $0.67 \mathrm{~cm}^{2}$ & $\mathrm{p}<0.05$ \\
VOL 1 $\left(\mathrm{cm}^{3}\right)$ & $1.77 \mathrm{~cm}^{3}$ & $1.81 \mathrm{~cm}^{3}$ & $\mathrm{p}<0.05$ \\
\hline MCA 2 $\left(\mathrm{cm}^{2}\right)$ & $0.56 \mathrm{~cm}^{2}$ & $0.62 \mathrm{~cm}^{2}$ & $\mathrm{p}<0.05$ \\
VOL 2 $\left(\mathrm{cm}^{3}\right)$ & $3.37 \mathrm{~cm}^{3}$ & $3.49 \mathrm{~cm}^{3}$ & n.s. \\
\hline
\end{tabular}

can influence the intranasal climate directly via the inhaled cold air and indirectly by cold stimulation of the facial skin.

Temperature differences on the body surface are perceived by thermal receptors. Cold receptors are superficial and are partially associated with fast-conducting myelinated fibers; thus, cold stimuli are perceived faster than heat stimuli. Thermal receptors are distributed with varying densities over different areas. The highest density of receptors is found in the sensory area of the trigeminal nerve in the region of mouth and nose ${ }^{(12)}$. Cold receptor density in the skin of the cheek is 2.7 receptors per square centimetre; in the intranasal mucosa it is 3.5 receptors per square centimetre ${ }^{(12)}$. Fouke et al. ${ }^{(13)}$ were able to measure changes in the temperature of buccal mucosal after facial cooling. Porter et al. ${ }^{(14)}$ showed that the effect of cooling depends on the location of the cold stimulus. In their study, the blood flow of the nasal mucosa was measured with a laser Doppler before and after ice cooling of the forehead and the oral cavity. The blood flow of the inferior turbinate was significantly increa-sed after intraoral cooling compared to brow cooling. A higher number of thermal receptors in the mouth might be responsible for this difference.

In this context, even the incidence of acute upper respiratory tract infections (URTI) seems to be affected by different types of cold exposures in the facial area and the upper airways. Eccles et al. discussed four types of cold stimulus and examined possible mechanisms for any relationship to URTI. A relationship between breathing cold air and cooling the body surface with the development of URTI seems to be possible, but is still discussed controversially. On the other hand, no evidence was found to support any relationship between ingestion of cold drinks / food or hypothermia and URTI (15).

Facial skin, oral surface as well as nasal mucosa are supplied by the trigeminal nerve. The trigeminal system received little attention clinically, even though the perception of nasal airflow is mediated through the trigeminal nerve. Therefore, the perception of inhaled menthol in the nose leads to a subjective improvement in nasal breathing due to stimulation of cold receptors supplied by the trigeminal nerve and not by widening the nasal cavity ${ }^{(9)}$. The automated assessment of $\mathrm{CO}_{2}$-pain responsiveness 
is a new technique in order to investigate the intranasal trigeminal system applying the irritant $\mathrm{CO}_{2}{ }^{(16)}$.

Due to this nervale linkage between facial skin and nasal mucosa, it would be conceivable that cooling of the skin influences nasal surface temperature, air conditioning, geometry as well as airflow. Therefore, the aim of the presented study was to identify intranasal adjustment mechanisms mediated by temperature changes of the facial skin induced by application of a cold face mask. We could not find any comparable studies in the literature examining the influence of temperature changes of the facial skin on intranasal characteristics.

Since the nasal mucosa and the facial skin are innervated by branches of the trigeminal nerve, there appears to be an intimate connection between the stimulus and response locations. It was obvious that the temperature of the nasal mucosa is affected by a cold stimulus to the facial skin.

The facial skin temperature decreased about $10^{\circ} \mathrm{C}$ after wearing the cooling mask. Intranasal air temperature did not change significantly and was not expected to. However, absolute humidity of intranasal air and nasal mucosal temperature were significantly higher after wearing the mask. Higher nasal mucosal temperature and widened cross-sectional area could be detected.

The influence of different exposed parameters of inhaled air on nasal functions has been analysed ${ }^{(15,17-21)}$. These studies showed that posture, different air temperatures/humidities and climatic conditions mainly lead to changes in the nasal mucosa temperature. In this study, we wanted to examine in particular, if a selective thermal stimulation of the facial skin leads to significant changes within the nose via a possible trigeminal link. This should continue our previous investigations ${ }^{(16,17)}$ from a different perspective. In accordance we could demonstrated an increased nasal mucosal temperature after cooling of the entire facial skin. Intensive warming of the nasal mucosa creates the necessary heat gradient between mucosa and air to increase the moisture capacity of the inhaled air. The heat energy of the mucosa can be transferred more efficiently to moist air than to dry air. In our study the absolute humidity of the air increased significantly after wearing the cooling mask as humid air is an excellent heat conductor.

In addition to increased mucosal temperature and absolute humidity, the acoustic rhinometric results showed a significant increase of the cross-sectional areas and the volumes, especially in the anterior nose (MCA 1 and 2, Vol 1). Although at first sight this seems to be contradictory, this widening of the nasal valve might be intended to influence the climatization performance in the posterior areas of the nose due to changes in the inflow. These geometric changes in the nasal entrance produced changes of intranasal airflow and resulted in changes of air conditioning shown in our numerical simulations ${ }^{(1,23,24)}$. The in general missing correlation between the values of the acoustic rhinometry and the active anterior rhinomanometry could explain the missing change in nasal airflow volume.

Our investigation demonstrates the interaction between an external cold stimulus and intranasal mucosal changes that influence heat and humidity transfer within the nose. The observed changes in acoustic rhinometry support this relationship. By changing the cross-sectional inflow areas in the nose, the airflow is modified and the conditioning capacity of the nose is increased.

\section{Conclusion}

Climatic conditions influence intranasal air conditioning and ultimately ensure optimal pulmonary gas exchange. A brief facial cold stimulus leads to reactive warming of the nasal mucosa. Increase of mucosal temperature, humidity of intranasal air and changes in the inflow volume of the nose appear to support constant heating and humidification of inhaled air. The increased humidity acts as a thermal conductor allowing the heat energy of the nasal mucosa to be efficiently transferred to the inhaled air. Despite the external cold stimulus, temperature of the inhaled air remained relatively constant. The described intranasal changes might be induced by the irritation of the trigeminal nerve as facial skin and nasal mucosa are both supplied by the trigeminal nerve. The cross-sectional area at the nasal valve influences acclimatization of inhaled air to subsequent portions of the respiratory tract.

\section{Authorship contribution}

J.L. designed the research. J.L., A.K., E.M.W., and F.S. performed the measurements. J.L. and F.S. wrote the manuscript. T.H. analyzed results and performed final editing.

\section{Conflict of interest}

Authors declare no conflict of interest.

\section{References}

1. Lindemann J, Keck T, Wiesmiller KM, Rettinger G, Brambs HJ, Pless D. Numerical simulation of intranasal air flow and temperature after resection of the turbinates during inspiration. Rhinology 2005; 43: 24-28.

2. Lindemann J, Keck T, Wiesmiller K, et al. A numerical simulation of intranasal air temperature during inspiration. Laryngoscope 2004; 114: 1037-1041.

3. Keck T, Leiacker R, Riechelmann $H$, et al. Temperature profile in the nasal cavity. Laryngoscope 2000; 110: 651-654.

4. Keck T, Leicker R, Heinrich A, et al. Humidity and temperature profile in the nasal cavity.
Rhinology 2000; 38:167-171.

5. Carey JW, and Steegmann AT Jr. Human nasal protrusion, latitude, and climate. Am J Phys Anthropol 1981; 56: 313-319.

6. Franciscus RG, and Trinkaus E. Nasal morphology and the emergence of Homo erectus. Am J Phys Anthropol 1988; 75: 517-527.

7. Seren E, Seren S. Morphological adapta- 
tion of the nasal valve area to climate Med Hypotheses. 2009; 72: 471-2.

8. Lindemann J, Keck T, Leiacker R, et al. Nasal mucosal temperature in relation to nasal airflow as measured by rhinomanometry. Am J Rhinol 2007;21: 46-49.

9. Lindemann J, Tsakiropoulou E, Scheithauer MO, Konstantinidis I, Wiesmiller KM. Impact of menthol inhalation on nasal mucosal temperature and nasal patency. Am Rhinol 2008; 22: 402-405.

10. Lindemann J, Leiacker R, Rettinger $\mathrm{G}$, et al Nasal mucosal temperature during respiration. Clin Otolaryngol 2002; 27: 135-139.

11. Clement PAR, Gordts F. Consensus reports on acoustic rhinometry and rhinomanometry. Rhinology 2005; 43: 169-179

12. Jones AS, Wight RG, Durham LH: The distribution of thermoreceptors within the nasal cavity. Clin Otolaryngol 1989; 14: 235-239.

13. Fouke JM, Wolin AD, Bowman HF, McFadden ER: Effect of facial cooling on mucosal blood flow in the mouth in humans. Clinical Science 1990; 79: 307-313

14. Porter M, Marais J, Tolley N: The effect of ice packs upon nasal mucosal blood flow. Acta Otolaryngol 1991; 111:1122-1125.

15. Eccles R, Wilkinson JE. Exposure to cold and acute upper respiratory tract infection. Rhinology. 2015; 53: 99-106.
16. Hummel T, Kaehling C, Grosse F. Automated assessment of intranasal trigeminal function. Rhinology. 2016; 54: 27-31.

17. Lal D, Gorges ML, Ungkhara G, Reidy PM Corey JP: Physiological change in nasa patency in response to changes in posture, temperature, and humidity measured by acoustic rhinometry. Am J Rhinol 2006; 20: 456-462.

18. Liener K, Leiacker R, Lindemann J, Rettinger G, Keck T: Nasal mucosal temperature after exposure to cold, dry air and hot, humid air. Acta Otolaryngol 2003; 123: 851-856.

19. Keck T, Leiacker R, Lindemann J, Rettinger G Kühnemann S: Endonasal temperature and humidity profile after exposure to different climatic conditions. HNO 2001; 49: 372-377.

20. Naclerio RM, Proud D, Kagey-Sobotka A, Lichtenstein LM, Thompson M, Togias A: Cold dry air-induced rhinitis: effect of inhaation and exhalation through the nose. Appl Physiol 1995; 79: 467-471.

21. Olsson P, Bende M: Influence of environmental temperature on human nasal mucosa. Ann Otol Rhinol Laryngol 1985; 94: 153155.

22. Iliopoulos $O$, Proud D, Norman $P$ Lichtenstein L, Kagey-Sobotka A, Naclerio RM: Nasal challenge with cold, dry air induces a late phase reaction. Am Rev
Respir Dis 1988; 138: 400-405.

23. Lindemann J, Rettinger $G$, Kroeger $R$ Sommer F. Numerical simulation of airflow patterns in nose models with differently localized septal perforations. Laryngoscope 2013; 123: 2085-9.

24. Sommer F, Kroger R, Lindemann J. Numerical simulation of humidification and heating during inspiration within an adult nose. Rhinology. 2012; 150:157-164.

\section{Prof. Dr. Joerg Lindemann}

Department of Otorhinolaryngology

Head and Neck Surgery

University Hospital of Ulm

Frauensteige 12

D- 89075 Ulm

Germany

Tel: +49-731-50059501

Fax: $+49-731-50059810$

Email:

joerg.lindemann@uniklinik-ulm.de 